\title{
Toenail selenium as an indicator of environmental exposure: A cross-sectional study
}

\author{
TOMMASO FILIPPINI ${ }^{1}$, ANGELA FERRARI ${ }^{1}$, BERNHARD MICHALKE ${ }^{2}$, PETER GRILL $^{2}$, \\ LUCIANO VESCOVI $^{3}$, CHIARA SALVIA ${ }^{1}$, CARLOTTA MALAGOLI ${ }^{1}$, MARCELLA MALAVOLTI ${ }^{1}$, \\ SABINA SIERI ${ }^{4}$, VITTORIO KROGH ${ }^{4}$, ANNALISA BARGELLINI ${ }^{1}$, ANTONIO MARTINO $^{1}$, \\ MARGHERITA FERRANTE ${ }^{5}$ and MARCO VINCETI ${ }^{1}$ \\ ${ }^{1}$ CREAGEN, Environmental, Genetic and Nutritional Epidemiology Research Center, Section of Public Health, \\ Department of Biomedical, Metabolic and Neural Sciences, University of Modena and Reggio Emilia, \\ I-41125 Modena, Italy; ${ }^{2}$ Helmholtz Zentrum München, Research Unit Analytical BioGeoChemistry, \\ D-85764 Neuherberg, Germany; ${ }^{3}$ Laboratory of Environmental Chemistry, IREN, I-42123 Reggio Emilia; \\ ${ }^{4}$ Epidemiology and Prevention Unit, Fondazione IRCCS Istituto Nazionale dei Tumori, I-20133 Milan, \\ ${ }^{5}$ Department of Medical, Surgical Sciences and Advanced Technologies 'G.F. Ingrassia', \\ University of Catania, I-95123 Catania, Italy
}

Received December 30, 2016; Accepted February 9, 2017

DOI: $10.3892 / \mathrm{mmr} .2017 .6388$

\begin{abstract}
The relation between toxicity and essentiality of selenium (Se) is of growing interest in human health, as the effects may widely differ depending of its different chemical species and the exposure levels. Toenail Se has been proposed as a reliable biomarker of long-term Se exposure, but few studies investigated the correlation between its toenail content and environmental determinants (i.e., dietary food intake). We aimed to determine the relation of toenail Se levels with serum Se species as well as food items. We recruited a random sample of Modena (Northern Italy) municipal residents, from whom we collected detailed personal information, dietary habits, toenail specimen for Se determination and a blood sample for serum Se speciation analysis. Toenail Se mean value was $0.96 \mu \mathrm{g} / \mathrm{g}$ (range, $0.47-1.60$ ), with slightly higher levels in females, in non-obese subjects and in Se supplements users, while it was lower in current smokers. Toenail Se positively correlated with organic Se forms, mainly selenoprotein $\mathrm{P}$ and selenocysteine, and inversely with the inorganic forms (selenite and selenate). Toenail Se was not associated with meat, cereals and dairy products consumption, positively correlated with fruit and slightly
\end{abstract}

Correspondence to: Professor Marco Vinceti, CREAGEN, Environmental, Genetic and Nutritional Epidemiology Research Center, Section of Public Health, Department of Biomedical, Metabolic and Neural Sciences, University of Modena and Reggio Emilia, Via Campi 287, I-41125 Modena, Italy

E-mail: marco.vinceti@unimore.it

Key words: selenium, toenail, serum, speciation analysis, dietary intake, cross-sectional study with vegetable intake, and negatively with fish and seafood consumption. Finally, no clear association emerged with estimated air Se exposure.

\section{Introduction}

Selenium (Se) is a metalloid showing an intriguing relation with human health, particularly with cancer $(1,2)$ and with other diseases $(3,4)$. The main source of Se exposure is the dietary intake, closely linked to Se content in soil. Conversely, the contribution of other environmental sources is generally negligible, although few studies outlined higher risk of neurologic disease in areas with high levels of Se in drinking water (5-7) and higher risk of cardiovascular hospitalization (8) and hematological malignancies (9) due to higher exposure to Se air levels. The primary dietary sources of Se in the Italian diet is derived from meat, fish, cereals and dairy products $(10,11)$. Nevertheless, an accurate assessment of Se intake based on individual food consumption is very difficult and dietary assessment tools could fail to adequately measure Se intake because foodstuff Se content changes according to the geographic variations of soil Se concentration $(10,12)$ and the capacity of plants to absorb it (13). Furthermore, dietary supplements may contribute substantially to Se intake and body tissue content (14).

Se exposure has been assessed in epidemiologic studies through several biomarkers, including its concentrations in blood cells, serum or plasma, urine, hair and nails (15-19). Toenail Se has been largely investigated as a surrogate of Se intake $(20,21)$ as toenail sample may represent a useful biomarker for long-term Se exposure given the slow growth rate (22) and has the advantage to be easily collected being not invasive (23). Determinants of toenail Se levels have been investigated in some studies $(20,24-26)$, but only a few assessed the influence of specific foodstuffs on toenail Se 
content $(10,27)$ and as far as we know no such study examined its relation with circulating Se species.

In this study we assessed the levels of toenail Se in a representative sample of Northern Italian population, exploring the influence of demographic characteristics, lifestyles and dietary intake of selected food and of serum Se species, and finally environmental air Se levels.

\section{Materials and methods}

Study population. The methodology for the recruitment of the study population was previously described $(18,28)$. Briefly, following the approval of local Ethics Committee, we recruited a random sample of 50 subjects residing in Modena, using the Stata 'sample' routine (Stata 11; Stata Corporation, College Station, TX, USA) out of the list of eligible subjects from each gender- and age-specific subgroup, by accessing the databases of the Modena Municipality General Registry Office. We contacted these subjects in 2011 by phone asking for their participation in the study. Subjects who accepted to participate were invited to the Modena Health Unit to give a venous blood sample in morning fasting state. After the collection of their written consent, the blood sample was collected in a plastic tube (BD 368815 Vacutainer ${ }^{\circledR}$ Plus plastic serum tube with red BD Hemograd ${ }^{\mathrm{TM}}$ closure; Becton Dickinson SpA), immediately centrifuged at $1,000 \times \mathrm{g}$ for $10 \mathrm{~min}$ and serum aliquots of $1 \mathrm{ml}$ were stored at $-15^{\circ} \mathrm{C}$ until use. Moreover, we collected a sample of toenails using the procedure already adopted in previous studies (29-31). To summarize, we asked study subjects to yield a sample of their toenails, after letting them grow for two weeks and avoiding the use of chemical substances such as nail varnish or other specific nail products.

We collected from all study participants general information including smoking habits, education, occupational history and use of dietary supplements. Secondly, we assessed their dietary habits through a semi-quantitative food frequency questionnaire used for the Central-Northern Italian population within the EPIC study (32). This questionnaire assessed the frequency and amount of consumption of 188 food items over the previous year, and allowed the frequency and quantity of consumption of foodstuffs and the related intake of nutrients and contaminants to be calculated using the Italian version of the EPIC-Soft program (EPIC Project, Milan, Italy) $(33,34)$.

\section{Laboratory analysis}

Toenail sample. We stored the toenail clippings in a PPL tube (inert polypropylene tubes with pressure cap; Incofar S.R.L., Modena, Italy), and before analysis we washed the specimens using a 5\% Triton X-100 solution in deionized water (Sigma-Aldricht, Darmstadt, Germany), we sonicated them for $15 \mathrm{~min}$ and after this we rinsed and sonicated the samples again for $15 \mathrm{~min}$ in deionized water. We dried the nails at $105^{\circ} \mathrm{C}$ for $3 \mathrm{~h}$ and we digested the samples, weighing from 24.8 to $401.0 \mathrm{mg}$, in the Microwave Laboratory system (Milestone ETHOS-TC, Shelton, CT, USA) using $7 \mathrm{ml}$ of $\mathrm{HNO}_{3}$ 69\% (nitric acid, 69\%; Merck Suprapur ${ }^{\mathrm{TM}}$, Darmstadt, Germany), $2 \mathrm{ml}$ of $\mathrm{H}_{2} \mathrm{O}_{2} 30 \%$ (hydrogen peroxide, $30 \%$; Merck Perhydrol, Darmstadt, Germany). We finally transferred the cooled samples into a $25 \mathrm{ml}$ flask (polyethylene flask; Incofar S.R.L.) and diluted with Milli-Q water (Millipore, Bedford, MA, USA).

We measured toenail Se content using a Zeeman-effect corrected graphite furnace atomic absorption spectrometer (AAnalyst 600; Perkin-Elmer Inc., Waltham, MA, USA). A transversely-heated graphite atomizer (THGA) graphite tube (Perkin-Elmer Inc., Waltham, MA, USA) with end cap was used at atomization temperature of $1,900^{\circ} \mathrm{C}$, with electrodeless discharge lamp current set at $270 \mathrm{~mA}$, wavelength at $196 \mathrm{~nm}$ and a low slit of $2.0 \mathrm{~nm}$. Matrix modifier used was $\mathrm{Pd}+\mathrm{Mg}\left(\mathrm{NO}_{3}\right)_{2}$. In order to overcome matrix interference, we used the standard addition calibration technique, by adding Se standard solutions to a pooled sample of digested toenails. We used two reference materials for quality control in each session, in both cases human hair, GBW 09101 (China National Analysis Center for Iron and Steel, CSRI, China) and CRM 397 (European Community Bureau of Reference, Geel, Belgium).

Serum species. Se speciation methodology has been describe in details elsewhere (18). To summarize, a $1 \mathrm{ml}$ serum aliquot for each study subject was transported by air courier deep frozen in dry ice to the laboratory of the Research Center for Environmental Health (Research Unit Analytical BioGeoChemistry, Neuherberg, Germany), and kept continuously frozen until use. We slowly thawed samples in a refrigerator at $4^{\circ} \mathrm{C}$, vortexed and subsequently analyzed them. Suprapure grade chemicals were used throughout. Selenite (Se-IV), selenate (Se-VI), selenomethionine (Se-Met), selenocysteine (Se-Cys), thioredoxin reductase (EC 1.8.1.9.)-bound selenium (Se-TrxR), glutathione peroxidase (EC 232-749-6)-bound selenium (Se-GpX), human serum albumin (HSA) and Tris buffer were from Sigma-Aldrich (Deisenhofen, Germany). Working standards of Se species were prepared daily from their stock standard solutions by appropriate dilution with Milli-Q water. Selenoprotein P (SePP) is not commercially available as a standard compound. We prepared SePP from serum using affinity chromatography (AFC), and purified AFC-SePP fraction by a mass-calibrated size exclusion chromatography (SEC) column, where SePP eluted at an RT calculated for $62 \mathrm{kDa}$. We analyzed total serum Se by graphite furnace atomic absorption spectrometry based on the method of the MAK collection-biomonitoring methods (35).

We determined Se species Se-IV, Se-VI, Se-Met, Se-Cys, Se-TrxR, Se-GpX, SePP and HSA-Se in serum samples using anion exchange chromatography (IEC) coupled with inductively coupled plasma dynamic reaction cell mass spectrometry (ICP-DRC-MS; NexION; Perkin-Elmer Inc., Sciex, Toronto, ON, Canada) according to methodologies previously established for biological matrices $(36,37)$. In general the IEC separation followed $\mathrm{Xu}$ et al (38), but was slightly modified as previously described (18).

We connected a Knauer 1100 Smartline inert Series gradient HPLC system (Knauer, Berlin, Germany) to an anion exchange column AG 11 (precolumn, 50x4 mm) + AS 11 (analytical column, 250x $2 \mathrm{~mm}$ I.D.) both from Thermo Fisher Scientific, Dionex (Idstein, Germany) for species separation. The sample volume was $100 \mu 1$. The mobile phases were: eluent A, $10 \mathrm{mM}$ Tris-HAc, $\mathrm{pH} 8.0$ and 
Table I. Distribution of toenail Se $(\mu \mathrm{g} / \mathrm{g})$ in total population and in selected group categories.

\begin{tabular}{|c|c|c|c|c|c|c|c|c|}
\hline Variables & $\begin{array}{c}\text { No. of } \\
\text { subjects }\end{array}$ & 5 th & 25 th & 50 th & 75 th & 95th & Mean (SD) & P-value \\
\hline Total & 50 & 0.63 & 0.82 & 0.93 & 1.11 & 1.48 & $0.96(0.24)$ & \\
\hline Gender & & & & & & & & 0.077 \\
\hline Male & 25 & 0.63 & 0.79 & 0.85 & 1.01 & 1.21 & $0.90(0.20)$ & \\
\hline Female & 25 & 0.66 & 0.89 & 0.98 & 1.18 & 1.48 & $1.02(0.26)$ & \\
\hline Age & & & & & & & & 0.463 \\
\hline$<50$ years & 23 & 0.57 & 0.84 & 0.93 & 1.17 & 1.48 & $0.99(0.26)$ & \\
\hline$\geq 50$ years & 27 & 0.65 & 0.73 & 0.92 & 1.09 & 1.36 & $0.94(0.22)$ & \\
\hline BMI & & & & & & & & 0.102 \\
\hline$<25$ & 23 & 0.71 & 0.84 & 0.92 & 1.21 & 1.48 & $1.02(0.26)$ & \\
\hline$\geq 25$ & 27 & 0.57 & 0.79 & 0.93 & 1.04 & 1.24 & $0.91(0.21)$ & \\
\hline Se suppl. users & & & & & & & & 0.147 \\
\hline No & 40 & 0.60 & 0.80 & 0.93 & 1.09 & 1.32 & $0.94(0.22)$ & \\
\hline Yes & 10 & 0.79 & 0.85 & 0.93 & 1.24 & 1.60 & $1.06(0.28)$ & \\
\hline Smoking habits ${ }^{\mathrm{b}}$ & & & & & & & & 0.268 \\
\hline Never smokers & 26 & 0.71 & 0.83 & 0.92 & 1.09 & 1.24 & $0.96(0.22)$ & \\
\hline Former smokers & 15 & 0.65 & 0.85 & 0.99 & 1.18 & 1.48 & $1.03(0.25)$ & \\
\hline Current smokers & 9 & 0.47 & 0.66 & 0.87 & 1.01 & 1.28 & $0.86(0.25)$ & \\
\hline
\end{tabular}

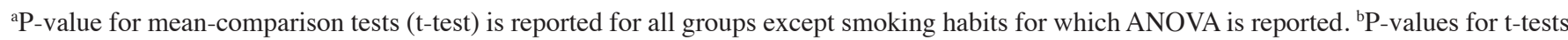
among smoking categories were $\mathrm{P}=0.142$ between former and current smokers; $\mathrm{P}=0.268$ between never and current smokers; and $\mathrm{P}=0.398$ between never and former smokers. Se, selenium; ANOVA, analysis of variance; suppl, supplement.

eluent B, A + $500 \mathrm{mM}$ NH4Ac, $\mathrm{pH} 8.0$. Gradient elution expressed as \%-eluent A: 0-3 min, 100\%; 3-10 min, 100-60\%; 10-23 $\mathrm{min}, 60-45 \%$; 23-26 $\mathrm{min}, 45-43 \%$; 26-28 $\mathrm{min}, 43-0 \%$; $28-52 \mathrm{~min}, 0 \%$ and $52-60 \mathrm{~min}, 100 \%$. The flow rate was $0.70 \mathrm{ml} / \mathrm{min}$. For internal standardization we mixed the column effluent with $1 \mu \mathrm{g} / \mathrm{l} \mathrm{Rh}$ (final concentration, Rh flow rate: $0.1 \mathrm{ml} / \mathrm{l}$ ) and directed to ICP-MS. The experimental settings chosen for ICP-DRC-MS (NexION; Perkin-Elmer Inc., Sciex) after optimization were: radio frequency power, $1250 \mathrm{~W}$; plasma gas flow, $151 \mathrm{Ar} / \mathrm{min}$; auxiliary gas flow, $1.051 \mathrm{Ar} / \mathrm{min}$; nebulizer gas flow, $0.941 \mathrm{Ar} / \mathrm{min}$; daily optimized, dwell time $300 \mathrm{msec}$, ions montored: $78 \mathrm{Se}, 80 \mathrm{Se}$, $103 \mathrm{Rh}, \mathrm{DRC}$ reaction gas: $\mathrm{CH}_{4}$ reaction at $0.58 \mathrm{ml} / \mathrm{min}$, DRC rejection parameter, $\mathrm{q}=0.6$.

We used the standard addition method for standard-retention-time matched identification of Se species and as QC means in quantification. Species identity was further confirmed using a 2D approach of IEC-capillary electrophoresis ('Biofocus 3000' capillary electrophoresis system; BioRad, Munich, Germany) equipped with an uncoated capillary (Chromatographie Service GmbH, Langerwehe, Germany) $120 \mathrm{~cm}$ x $50 \mu \mathrm{m}$ ID was used for CE-ICP-DRC-MS analysis as previously described (37). Species identification was regarded as acceptable when the species matched the standard compounds with both chromatography/electrophoretic techniques (match in first and second technique). We performed peak quantification from chromatograms by comparing peak areas with peak area calibration curves using Peakfit ${ }^{\mathrm{TM}}$ software (Systat Software Inc., San Jose, CA, USA). The limit of detection for all Se species in serum was $0.02 \mu \mathrm{g} / 1$. Quality control, inter laboratory analytical comparison and recovery determination of individual Se species have been reported in detail (18).

Statistical analysis. Percentiles distribution, mean and standard deviation were calculated for Se in toenails. As we found one sample with very high toenail Se content $(2.78 \mu \mathrm{g} / \mathrm{g})$, we considered it as an outlier probably due to contamination of the sample and we removed the subjects from the entire data analyses. Mean comparison t-test was performed according to specific subgroup categories, namely, gender, age $(<50$ and $\geq 50$ years), BMI $(<25$ and $\geq 25)$, use of Se supplements and smoking habits (never, former and current smokers). Pearson's coefficients along with $95 \%$ confidence intervals (CIs) were calculated between Se and continuous variables (namely age, BMI, serum Se species and food intake). Bivariate and multivariate regress models were performed in order to test the influence on toenail Se of serum Se species: i) a crude model; ii) a partial model adjusted for gender, age and storage time; and iii) a fully adjusted model adding Se supplement use.

All foodstuff were grouped according to INN-CA patterns (39) in cereals, meat, fish and seafood, dairy products, sweets, vegetables, legumes, fruits and dry fruits. In order to reduce the influence of measurement errors frequently associated with the use of food frequency questionnaires, by decreasing artificial inter-individual variation introduced by under and over-reporting of food intake, we adjusted the estimates, for total energy intake, using the Willett's residual method (40). Pearson's correlation between toenail Se and 
A

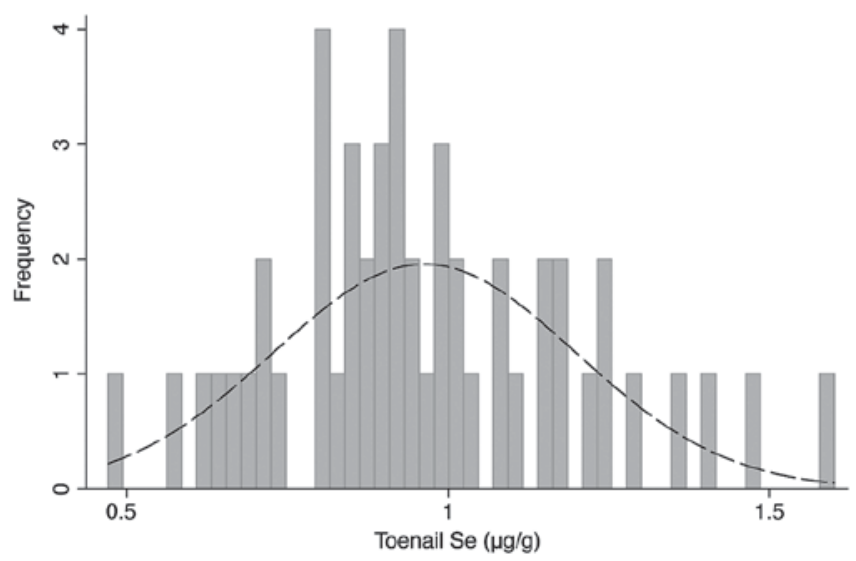

B

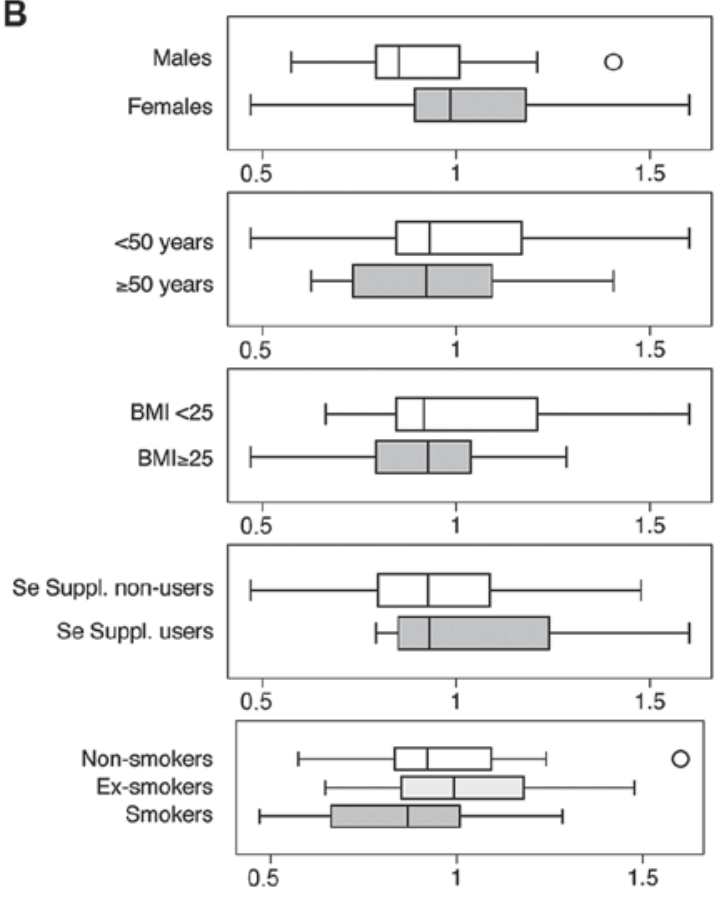

Figure 1. (A) Distribution of toenail Se $(\mu \mathrm{g} / \mathrm{g})$ in overall population. (B) Box plots distribution for selected subgroups. Se, selenium.

Table II. Pearson's correlation coefficient (r) between toenail Se and serum Se species.

\begin{tabular}{lrcc}
\hline Species & r & $95 \%$ CI & P-value \\
\hline Total Se & 0.036 & -0.248 to 0.314 & 0.809 \\
Inorganic Se & -0.254 & -0.499 to 0.030 & 0.079 \\
Se-IV & -0.222 & -0.474 to 0.063 & 0.125 \\
Se-VI & -0.255 & -0.500 to 0.028 & 0.077 \\
Organic Se & 0.262 & -0.020 to 0.506 & 0.069 \\
SePP & 0.131 & -0.156 to 0.398 & 0.370 \\
Se-Met & -0.171 & -0.432 to 0.115 & 0.239 \\
Se-Cys & 0.119 & -0.168 to 0.387 & 0.415 \\
Se-HSA & 0.056 & -0.229 to 0.332 & 0.703 \\
Se-GpX & 0.079 & -0.207 to 0.352 & 0.590 \\
Se-TrxR & 0.022 & -0.260 to 0.302 & 0.878 \\
Uknown species & -0.082 & -0.355 to 0.204 & 0.574 \\
\hline
\end{tabular}

Se, selenium.

residue of dietary intake and estimated dietary Se intake were performed. Between toenail Se and dietary products we performed also three regression models: i) adjusted only for energy intake (crude); ii) partial adjusted for energy intake, gender and age; and iii) fully adjusted, adding use of Se supplement. Sensitivity analyses adding smoking habits (coded as 0,1 and 2 for never, former and current smokers, respectively) and BMI were tested. Finally, the environmental source of Se through air was tested using levels of particulate matter $<10 \mu \mathrm{m}\left(\mathrm{PM}_{10}\right)$ estimated with a methodology previously reported for other trace elements [i.e., cadmium (28) and manganese in this issue (41)].
Table III. Pearson's correlation coefficient (r) between toenail Se and different food intake.

\begin{tabular}{lrcc}
\hline Categories & r & $95 \%$ CI & P-value \\
\hline Cereals & 0.015 & -0.268 to 0.295 & 0.920 \\
Meat & -0.053 & -0.329 to 0.232 & 0.718 \\
Fish and seafood & -0.161 & -0.423 to 0.126 & 0.270 \\
Dairy products & 0.020 & -0.263 to 0.299 & 0.893 \\
Sweets & -0.177 & -0.437 to 0.109 & 0.223 \\
Vegetables & 0.151 & -0.136 to 0.415 & 0.299 \\
Legumes & -0.001 & -0.282 to 0.280 & 0.993 \\
Fruits & 0.155 & -0.132 to 0.418 & 0.287 \\
Dry fruits & 0.015 & -0.267 to 0.295 & 0.917 \\
\hline
\end{tabular}

Se, selenium.

\section{Results}

Characteristic of study subjects were described in previous studies $(18,28)$. To summarize, age ranged from 35 to 70 years, and males and females were almost equally represented. Regarding occupational status, six were employed in the engineering industry, half in tertiary sector (mainly workers in the health system, education and business), while ten were retired and two were housewives. Ten subjects reported a current ongoing consumption of dietary supplements containing Se, corresponding to an average Se daily additional intake of $28.6 \mu \mathrm{g}$. Twenty-six were never smokers, fifteen were former smokers, all but one for over 10 years, while nine were current smokers. Pack-year mean (SD) values were similar, namely $14.0(10.2)$ and 13.9 (9.8) for former and current smokers, 

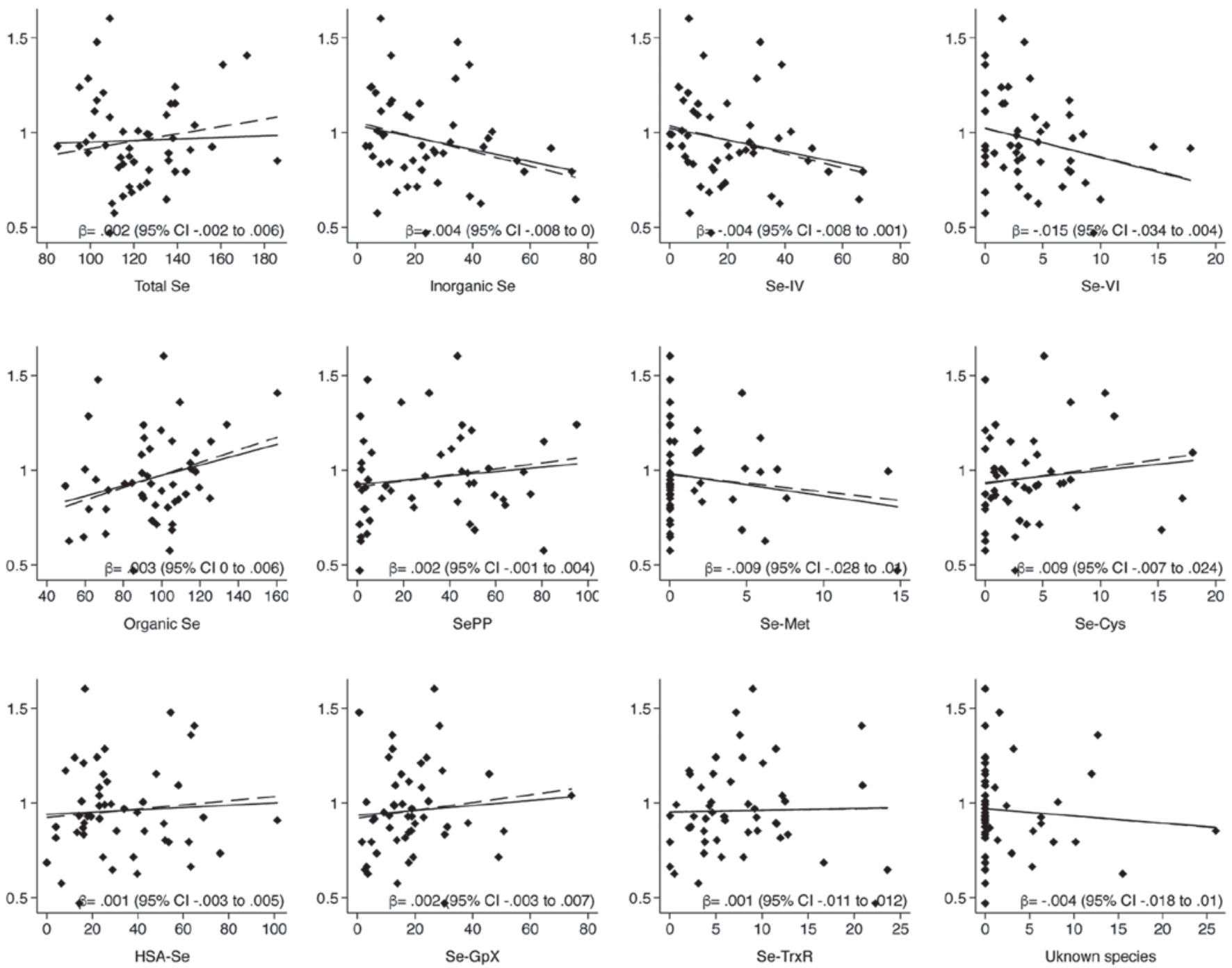

Figure 2. Linear regression between toenail Se (dependent variable in $\mu \mathrm{g} / \mathrm{g}$ ) and serum Se total and species ( $\mu \mathrm{g} / \mathrm{l})$. Crude model (solid line) and fully adjusted model for gender, age, storage time (in months) and use of Se supplements (dash line with $\beta$ coefficient) presented. Se, selenium.

respectively. Overall toenail Se mean was $0.96 \mu \mathrm{g} / \mathrm{g}$, ranged from 0.47 to $1.60 \mu \mathrm{g} / \mathrm{g}$, with slightly higher levels in females, in normal weight subjects and in those taking supplements containing Se (Table I and Fig. 1). Pearson's coefficients between toenail Se and age showed an inverse correlation as well for BMI with coefficients of -0.169 (95\% CI, -0.427 to $0.115 ; \mathrm{P}=0.241)$ for age and $-0.139(95 \% \mathrm{CI},-0.500$ to -0.262 ; $\mathrm{P}=0.017)$ for $\mathrm{BMI}$, respectively. In smoking habits, former smokers showed higher levels followed by never and current smokers.

Pearson's correlations between toenail Se and serum levels of total Se and its species (Table II) showed a positive relation with organic Se species, mainly SePP and Se-Cys, while an inverse one with inorganic forms. Results of Se-Met showed opposite results due to high number of value below the detection limit. Linear regression models demonstrated similar results, also adjusting for possible confounders including use of Se supplements (Fig. 2). Alternatively, adding to the presented models smoking habits did not substantially change the estimates (data not shown). Correlations with food items showed a direct relation only with fruits and slightly with vegetables, whilst a negative one with fish and sweets, and finally null for all other foodstuff (Table III). Linear regression models (crude and adjusted for energy intake, age, gender and use of Se supplement) demonstrated similar results (Fig. 3).

Similarly, Pearson's correlation between toenail Se and $\mathrm{Se}$ intake estimated using the Epic FFQ showed little relation, a correlation coefficient of -0.164 (95\% CI, -0.0426 to 0.123 ; $\mathrm{P}=0.260$ ), while linear regression coefficients were -0.002 (95\% CI, -0.004 to $0.001 ; \mathrm{P}=0.236),-0.001$ (95\% CI, -0.004 to $0.001 ; \mathrm{P}=0.264)$ and $-0.001(95 \% \mathrm{CI},-0.004$ to 0.002 ; $\mathrm{P}=0.520$ ) in crude, partial and fully adjusted models, respectively. Toenail Se was not associated with personal exposure to outdoor air $\mathrm{PM}_{10}$, as Pearson's correlation was 0.048 (95\% CI, -0.233 to $0.322 ; \mathrm{P}=0.741$ ).

\section{Discussion}

This study provided toenail Se levels in a representative sample of Northern Italian population. Our results are in line with previous findings conducted on healthy subjects as we found higher levels of toenail Se in supplement users $(14,20,26,27,42)$ and in females $(26,43,44)$, although 

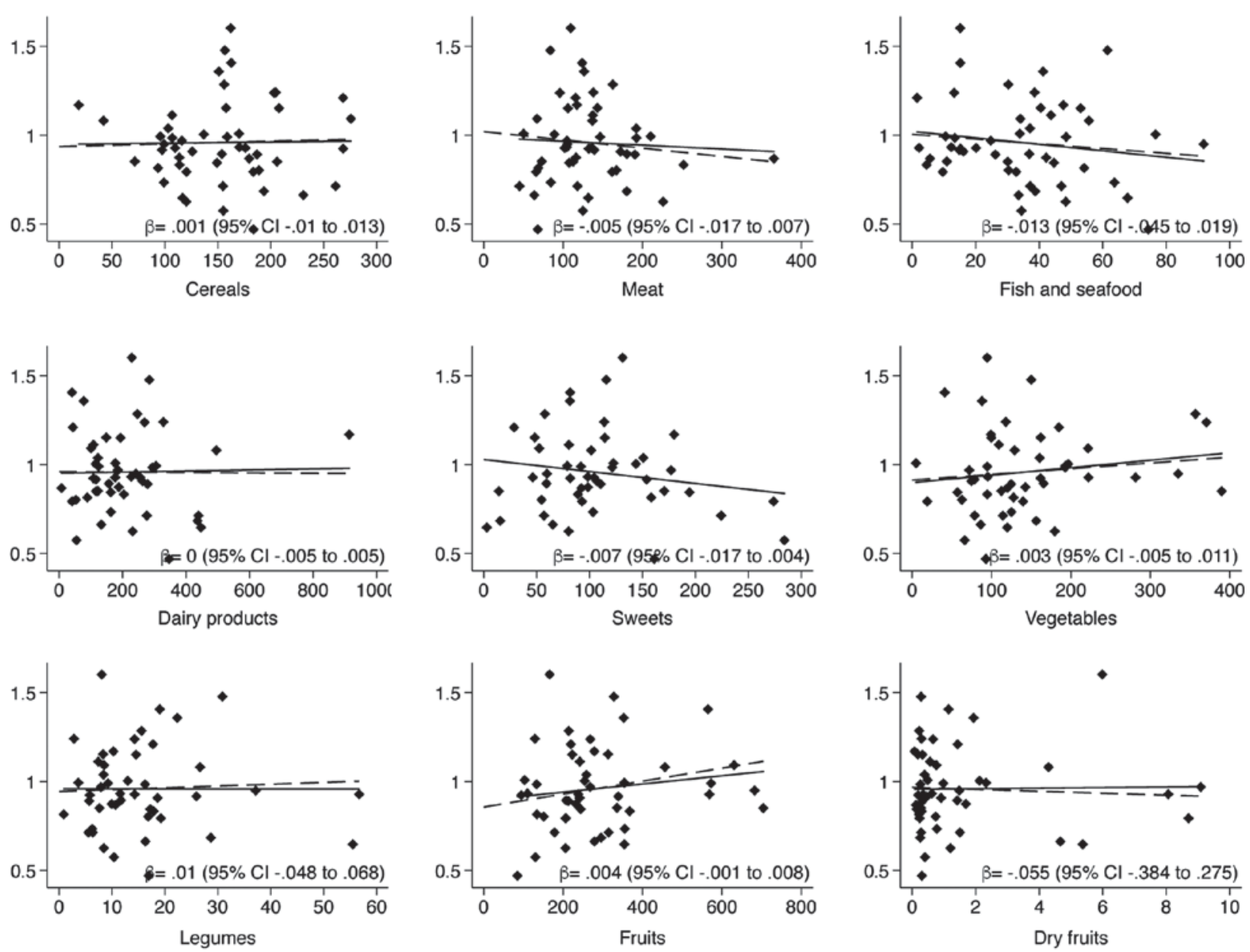

Figure 3. Scatter plots showing correlation between toenail Se $(\mu \mathrm{g} / \mathrm{g})$ and selected food categories ( $\mathrm{g} / \mathrm{day})$. Crude model (solid line) and fully adjusted model for gender, age, total energy intake and use of Se supplements (dash line with $\beta$ coefficient) presented.

some studies did not show any gender difference $(14,45)$ or conversely pointed out elevated Se exposure in males (27). Similarly, lower Se content was detected in current smokers respect to never and former smokers $(20,24-27,44,45)$, while age demonstrated a slight inverse relation reported in some $(24,27)$ but not in all studies $(20,25,26,45)$. Gender and genetics factors could play a role in influence Se toenail levels. A recent study carried out in different ethnic groups pointed out a positive correlation within Caucasian males but null in females, whilst inverse correlation was found in African females and again null in African males (44), although stratified analysis in our sample yielded similar negative correlation in both genders, with a stronger effect in females (data not shown).

Generally, studies correlating Se content in toenail with other biological indicators are performed comparing only total Se content $(14,21,45)$. We carried out an innovative analysis as we explored the relation between levels of toenail Se with total and individual Se serum species. Our peculiar analysis pointed out a positive relation with most of $\mathrm{Se}$ organic forms, mainly Se-PP and Se-Cys, while inverse with the inorganic forms. These results were confirmed after adjusting for possible confounders, including the use of $\mathrm{Se}$ supplements (Fig. 2). A possible explanation of the opposite behavior of organic and inorganic Se forms could be related to toenail composition. In fact, human nails are a modification of the skin, thus they are primary made of keratins, a family of proteins with an amino acid composition highly enriched in cysteine, thus they could accumulate Se either by binding to or by replacement of sulfhydryl sulfur $(46,47)$. Interestingly, a recent study of fingernail organic elemental composition found that females had higher levels of sulfur, while sulfur content did not vary with ageing (48).

Correlation of toenail Se and intake of different food expected to be major contributors of Se intake yielded inconclusive results. We found a null correlation with meat, dairy products and cereals, whilst an inverse correlation appeared for fish and seafood intake. A slight positive correlation was found with vegetable and fruit intake, but only the latter was confirmed in the multivariate model adjusted for potential confounders. Even in most human diets, the leading sources of Se are cereals, meats and fish, food intake estimated with frequency questionnaires or composition tables may have limited accuracy and reliability due to the wide variation of Se contents in food depending on geographical area $(1,17)$. About different Se species in food, the main form of Se in foods should be Se-Met which can be synthesized only by plants, while both plants and animals can incorporate Se-Met into proteins as a mimic for the correspondent sulfur-amino acid methionine (49). Studies conducted on edible seafood and canned tuna highlighted a higher fish content of Se-Met (29-70\%) and selenite/selenate (12-45\%) (50,51). A low 
fish intake in our sample is unlikely, as the median fish intake in our sample was $35 \mathrm{~g} /$ day (IQR, 15.5-47.4 g/day), similarly with those reported for other Italian populations $(11,39)$. Interestingly, a recent in vitro study by using a gastric and intestinal digestion methods, pointed out a low bioavailability of total Se and Se species from fish and seafood (52). Regarding milk and dairy products, the main Se species appear to be both Se-Cys and selenite (53), thus this could have influenced the null results. Finally, fruits and vegetables contain relatively small amounts of Se, with the possible exception of garlic, onion and cabbage (also defined 'Se accumulator'). An analysis splitting vegetables into Se accumulator and Se non-accumulator did not yielded different estimates (data not shown) (13).

The strengths of our study consists of the correlation toenail Se with the various Se serum species, yielding a switch from evaluation of overall content a trace element to the speciation analysis. The topic is of growing interest in medicine and biology, due to the different, and in some cases, opposite effects that could be carried by different species on target tissues, as already demonstrated for Se itself and other trace elements (18,54-56).

A few limitations of this study must be outlined. First, the retention of organic Se forms in body tissues is consistently higher than that of inorganic compounds (57), and therefore distribution of Se species in human tissues may not necessarily reflect the relative intake of these species through diet and other sources, nor their toxicity and biological effects (58). Moreover, the limited sample size of our study, which was a consequence of the difficulties in recruiting volunteers from the general population, reduced the statistical stability of the point estimates. However, despite this limitation, our study population still seems to represent the general Italian population as far as demographic characteristics and lifestyle factors are concerned $(59,60)$.

In conclusion, our cross-sectional analysis is to our knowledge the first that assessed the relation between Se levels in toenail with serum Se species, detecting an opposite behavior depending on the type of Se forms considered. Furthermore, it is one of the few studies that explored the influence of different food on Se toenail content, showing a null relation with cereals, meat and dairy products, a direct correlation only with fruits and a little with vegetables intake, whilst inverse relation with fish and seafood consumption, although more studies are needed. Finally, air Se exposure assessed through $\mathrm{PM}_{10}$ estimate levels, seemed to barely influence the toenail Se levels.

\section{References}

1. Vinceti M, Dennert G, Crespi CM, Zwahlen M, Brinkman M, Zeegers MP, Horneber M, D'Amico R and Del Giovane C: Selenium for preventing cancer. Cochrane Database Syst Rev 3: CD005195, 2014.

2. Vinceti M and Rothman KJ: More results but no clear conclusion on selenium and cancer. Am J Clin Nutr 104: 245-246, 2016.

3. Jablonska E and Vinceti M: Selenium and human health: witnessing a copernican revolution? J Environ Sci Health C Environ Carcinog Ecotoxicol Rev 33: 328-368, 2015.

4. Vinceti M, Burlingame B, Filippini T, Naska A, Bargellini A and Borella P: The epidemiology of selenium and human health In: Selenium: Its Molecular Biology and Role in Human Health. Hatfield DL, Schweizer U, Tsuji PA and Gladyshev VN (eds). Springer International Publishing, Cham, pp365-376, 2016.
5. Tsongas TA and Ferguson SW: Human health effects of selenium in a rural Colorado drinking water supply. In: Trace Substances in Environmental Health-XI. A Symposium. Hemphill DD (ed). University of Missouri, Columbia, pp30-35, 1977.

6. Valentine JL: Environmental occurrence of selenium in waters and related health significance. Biomed Environ Sci 10: 292-299, 1997.

7. Vinceti M, Ballotari P, Steinmaus C, Malagoli C, Luberto F, Malavolti M and Giorgi Rossi P: Long-term mortality patterns in a residential cohort exposed to inorganic selenium in drinking water. Environ Res 150: 348-356, 2016.

8. Ito K, Mathes R, Ross Z, Nádas A, Thurston G and Matte T: Fine particulate matter constituents associated with cardiovascular hospitalizations and mortality in New York City. Environ Health Perspect 119: 467-473, 2011.

9. Heck JE, Park AS, Qiu J, Cockburn M and Ritz B: Risk of leukemia in relation to exposure to ambient air toxics in pregnancy and early childhood. Int J Hyg Environ Health 217: 662-668, 2014.

10. Mariottini E, Capel R and Bigazzi Grasso C: Selenium content in foods. J Prev Med Hyg 36: 55-60, 1995.

11. Lombardi-Boccia G, Aguzzi A, Cappelloni M, Di Lullo G and Lucarini M: Total-diet study: dietary intakes of macro elements and trace elements in Italy. Br J Nutr 90: 1117-1121, 2003.

12. Shacklette HT and Boerngen JG: Element concentrations in soils and other surficial materials of the conterminous United States. U.S. Geological Paper 1270, United States Goverment Printing Office, Washington, 1984

13. Terry N, Zayed AM, De Souza MP and Tarun AS: Selenium in higher plants. Annu Rev Plant Physiol Plant Mol Biol 51: 401-432, 2000.

14. Satia JA, King IB, Morris JS, Stratton K and White E: Toenail and plasma levels as biomarkers of selenium exposure. Ann Epidemiol 16: 53-58, 2006.

15. Combs GF Jr, Watts JC, Jackson MI, Johnson LK, Zeng H, Scheett AJ, Uthus EO, Schomburg L, Hoeg A, Hoefig CS, et al: Determinants of selenium status in healthy adults. Nutr J 10: 75, 2011.

16. EFSA Panel on Dietetic Products, Nutrition and Allergies (NDA): Scientific opinion on dietary reference values for selenium. EFSA 12: 1-67, 2014.

17. Vinceti M, Crespi CM, Malagoli C, Del Giovane C and Krogh V: Friend or foe? The current epidemiologic evidence on selenium and human cancer risk. J Environ Sci Health C Environ Carcinog Ecotoxicol Rev 31: 305-341, 2013.

18. Vinceti M, Grill P, Malagoli C, Filippini T, Storani S, Malavolti M and Michalke B: Selenium speciation in human serum and its implications for epidemiologic research: a cross-sectional study. J Trace Elem Med Biol 31: 1-10, 2015.

19. Skalny AV, Simashkova NV, Klyushnik TP, Grabeklis AR, Radysh IV, Skalnaya MG and Tinkov AA: Analysis of hair trace elements in children with autism spectrum disorders and communication disorders. Biol Trace Elem Res: Oct 26, 2016 (Epub ahead of print).

20. Ovaskainen ML, Virtamo J, Alfthan G, Haukka J, Pietinen P, Taylor PR and Huttunen JK: Toenail selenium as an indicator of selenium intake among middle-aged men in an area with low soil selenium. Am J Clin Nutr 57: 662-665, 1993.

21. Longnecker MP, Stram DO, Taylor PR, Levander OA, Howe M, Veillon C, McAdam PA, Patterson KY, Holden JM, Morris JS, et al: Use of selenium concentration in whole blood, serum, toenails, or urine as a surrogate measure of selenium intake. Epidemiology 7: 384-390, 1996.

22. Yaemsiri S, Hou N, Slining MM and He K: Growth rate of human fingernails and toenails in healthy American young adults. J Eur Acad Dermatol Venereol 24: 420-423, 2010.

23. Krogh V, Pala V, Vinceti M, Berrino F, Ganzi A, Micheli A, Muti P, Vescovi L, Ferrari A, Fortini K, et al: Toenail selenium as biomarker: reproducibility over a one-year period and factors influencing reproducibility. J Trace Elem Med Biol 17 (Suppl 1): 31-36, 2003.

24. Hunter DJ, Morris JS, Chute CG, Kushner E, Colditz GA, Stampfer MJ, Speizer FE and Willett WC: Predictors of selenium concentration in human toenails. Am J Epidemiol 132: 114-122, 1990.

25. van den Brandt PA, Goldbohm RA, van't Veer P, Bode P, Hermus RJ and Sturmans F: Predictors of toenail selenium levels in men and women. Cancer Epidemiol Biomarkers Prev 2: 107-112, 1993. 
26. Morris JS, Spate VL and Ngwenyama RA: Determinants of selenium in the toenail biomonitor. J Radioanal Nucl Chem 269: 283-290, 2006.

27. Park K, Rimm E, Siscovick D, Spiegelman D, Morris JS and Mozaffarian D: Demographic and lifestyle factors and selenium levels in men and women in the U.S. Nutr Res Pract 5: 357-364, 2011

28. Filippini T, Michalke B, Malagoli C, Grill P, Bottecchi I, Malavolti M, Vescovi L, Sieri S, Krogh V, Cherubini A, et al: Determinants of serum cadmium levels in a Northern Italy community: a cross-sectional study. Environ Res 150: 219-226, 2016.

29. Bergomi M, Vinceti M, Nacci G, Pietrini V, Brätter P, Alber D Ferrari A, Vescovi L, Guidetti D, Sola P, et al: Environmental exposure to trace elements and risk of amyotrophic lateral sclerosis: a population-based case-control study. Environ Res 89: $116-123,2002$.

30. Vinceti M, Bassissi S, Malagoli C, Pellacani G, Alber D, Bergomi M and Seidenari S: Environmental exposure to trace elements and risk of cutaneous melanoma. J Expo Anal Environ Epidemiol 15: 458-462, 2005.

31. Vinceti M, Venturelli M, Sighinolfi C, Trerotoli P, Bonvicini F, Ferrari A, Bianchi G, Serio G, Bergomi M and Vivoli G: Case-control study of toenail cadmium and prostate cancer risk in Italy. Sci Total Environ 373: 77-81, 2007.

32. Pala V, Sieri S, Palli D, Salvini S, Berrino F, Bellegotti M, Frasca G, Tumino R, Sacerdote C, Fiorini L, et al: Diet in the Italian EPIC cohorts: presentation of data and methodological issues. Tumori 89: 594-607, 2003

33. Malavolti M, Malagoli C, Fiorentini C, Longo C, Farnetani F, Ricci C, Albertini G, Lanzoni A, Reggiani C, Virgili A, et al: Association between dietary vitamin $\mathrm{C}$ and risk of cutaneous melanoma in a population of Northern Italy. Int J Vitam Nutr Res 83: 291-298,2013

34. Malagoli C, Malavolti M, Agnoli C, Crespi CM, Fiorentini C, Farnetani F, Longo C, Ricci C, Albertini G, Lanzoni A, et al Diet quality and risk of melanoma in an Italian population. J Nutr 145: 1800-1807, 2015.

35. Heitland P: Selenium in serum. In: The MAK Collection for Occupational Health and Safety. Part IV: Biomonitoring Methods. Vol 13. Wiley-VCH, Germany, pp249-263, 2013.

36. Michalke B and Berthele A: Contribution to selenium speciation in cerebrospinal fluid samples. J Anal At Spectrom 26: 165-170, 2011

37. Solovyev N, Berthele A and Michalke B: Selenium speciation in paired serum and cerebrospinal fluid samples. Anal Bioanal Chem 405: 1875-1884, 2013.

38. Xu M, Yang LM and Wang QQ: Quantification of selenium-tagged proteins in human plasma using species-unspecific isotope dilution ICP-DRC-qMS coupled on-line with anion exchange chromatography. J Anal At Spectrom 23: 1545-1549, 2008.

39. Turrini A, Saba A, Perrone D, Cialfa E and D'Amicis A: Food consumption patterns in Italy: the INN-CA study 1994-1996. Eur J Clin Nutr 55: 571-588, 2001.

40. Willett W: Nutritional epidemiology. 3rd edition. Oxford University Press, New York, 2013.

41. Filippini T, Michalke B, Grill P, Malagoli C, Malavolti M, Vescovi L and Sieri S: Determinants of serum manganese levels in an Italian population. Mol Med Rep (In press).

42. Baskett CK, Spate VL, Mason MM, Nichols TA, Williams A, Dubman IM, Gudino A, Denison J and Morris JS: Long-term selenium status in humans. J Radioanal Nucl Chem 249: 429-435, 2001.

43. Kanabrocki EL, Kanabrocki JA, Greco J, Kaplan E, Oester YT, Brar SS, Gustafson PS, Nelson DM and Moore CE: Instrumental analysis of trace elements in thumbnails of human subjects. Sci Total Environ 13: 131-140, 1979.
44. Xun P, Bujnowski D, Liu K, Morris JS, Guo Z and He K: Distribution of toenail selenium levels in young adult Caucasians and African Americans in the United States: the CARDIA trace element study. Environ Res 111: 514-519, 2011.

45. Swanson CA, Longnecker MP, Veillon C, Howe M, Levander OA, Taylor PR, McAdam PA, Brown CC, Stampfer MJ and Willett WC: Selenium intake, age, gender, and smoking in relation to indices of selenium status of adults residing in a seleniferous area. Am J Clin Nutr 52: 858-862, 1990.

46. Block RJ: The composition of keratins. The amino acid composition of hair, wool, horn, and other eukeratins. J Biol Chem 128 181-186, 1939.

47. Magos L and Berg GG: Selenium. In: Biological Monitoring of Toxic Metals. Clarkson TW, Friberg L, Nordberg GF and Sager PR (eds). Plenum Press, New York, pp383-405, 1988.

48. Dittmar M, Dindorf W and Banerjee A: Organic elemental composition in fingernail plates varies between sexes and changes with increasing age in healthy humans. Gerontology 54 : 100-105, 2008

49. Schubert A, Holden JM and Wolf WR: Selenium content of a core group of foods based on a critical evaluation of published analytical data. J Am Diet Assoc 87: 285-299, 1987.

50. Cappon CJ and Smith JC: Chemical form and distribution of mercury and selenium in edible seafood. J Anal Toxicol 6: $10-21,1982$

51. Cappon CJ and Smith JC: Chemical form and distribution of mercury and selenium in canned tuna. J Appl Toxicol 2: 181-189, 1982.

52. Moreda-Piñeiro J, Moreda-Piñeiro A, Romarís-Hortas V, Domínguez-González R, Alonso-Rodríguez E, López-Mahía P, Muniategui-Lorenzo S, Prada-Rodríguez D and Bermejo Barrera P: In vitro bioavailability of total selenium and selenium species from seafood. Food Chem 139: 872-877, 2013

53. Muñiz-Naveiro O, Domínguez-González R, Bermejo-Barrera A, Bermejo-Barrera P, Cocho JA and Fraga JM: Selenium speciation in cow milk obtained after supplementation with different selenium forms to the cow feed using liquid chromatography coupled with hydride generation-atomic fluorescence spectrometry. Talanta 71: 1587-1593, 2007.

54. Vinceti M, Solovyev N, Mandrioli J, Crespi CM, Bonvicini F, Arcolin E, Georgoulopoulou E and Michalke B: Cerebrospinal fluid of newly diagnosed amyotrophic lateral sclerosis patients exhibits abnormal levels of selenium species including elevated selenite. Neurotoxicology 38: 25-32, 2013

55. Michalke B and Fernsebner K: New insights into manganese toxicity and speciation. J Trace Elem Med Biol 28: 106-116, 2014.

56. Michalke B: Review about the manganese speciation project related to neurodegeneration: an analytical chemistry approach to increase the knowledge about manganese related parkinsonian symptoms. J Trace Elem Med Biol 37: 50-61, 2016.

57. Fairweather-Tait SJ, Collings R and Hurst R: Selenium bioavailability: current knowledge and future research requirements. Am J Clin Nutr 91: 1484S-1491S, 2010.

58. Vinceti M, Maraldi T, Bergomi M and Malagoli C: Risk of chronic low-dose selenium overexposure in humans: insights from epidemiology and biochemistry. Rev Environ Health 24: 231-248, 2009.

59. Gruppo Tecnico PASSI Emilia-Romagna: Sovrappeso e obesità in Emilia-Romagna: dati del sistema di sorveglianza PASSI (anni 2008-2011), 2012 (In Italian).

60. Ferrante G, Minardi V, Possenti V, Quarchioni E, Masocco M, Salmaso S, Braggion M, Campostrini S and Baldissera S; Gruppo Tecnico PASSI: Smoke: prevalence is decreasing, but the gap between socioeconomic categories remains. Epidemiol Prev 36: 371, 2012 (In Italian). 